\title{
SOME ASPECTS OF GENERAL ACTIVITY, FORAGING AND BREEDING IN ICHTHYOPHIS BEDDOMEI (PETERS) AND ICHTHYOPHIS MALABARENSIS (TAYLOR) (APODA: ICHTHYOPHIIDAE) IN CAPTIVITY
}

\author{
Gopalakrishna Bhatta
}

Department of Zoology, Sri J.C.B.M. College, Sringeri, Karnataka 577139, India

\section{Introduction}

Amphibians are the first land dwelling vertebrates. Even though the class Amphibia includes three orders viz. Anura, Urodela and Gymnophiona, the present day knowledge of amphibian biology is mainly based on the studies of anurans (frogs and toads) and urodeles (salamanders and newts). Difficulty in studying is the root cause for scientific ignorance about caecilian. Caelilians are rarely encountered by casual naturalists due to their burrowing, secretive and nocturnal habits. Deliberate search (Bhatta 1997, 1998) in their preferential habitats is a prerequisite for understnding their natural history. Rearing these burrowing animals in captivity is also a difficult task, which requires maintenance of an environment similar to their natural habitat. Nevertheless, some individuals were reared in captivity with adequate efforts to study the general behaviour of these interesting creatures which is hitherto unknown. Some of the observations are discussed in the light of recent doubts and debates (Wake, 1977; Wilkinson, 1983; Nussbaum, 1984; Breckenridge et al., 1987).

\section{Materials and Methods}

Individuals of Ichthyophis beddomei and I. malabarensis were procured from Sringeri environs $\left(13^{\circ} 15^{\prime}-13^{\circ} 36^{\prime} \mathrm{N}\right.$ lat. and $75^{\circ} 4^{\prime}$ $75^{\circ} 22^{\prime} \mathrm{E}$ long.), reared in terraria each measuring $1 \mathrm{~m}^{3}$. The terraria were maintained at normal laboratory conditions of light and temperature. Each terrarium contained $15 \mathrm{~cm}$. thick substratum of moist humus rich soil obtained from the habitat of the species. The soil was periodically changed. The individuals were studied over a period of two years (1995-97) for general activity, feeding and breeding behaviours. They were fed with locally available species of earthworms once a week. Individuals were observed at night once a week at two hour intervals from $2000 \mathrm{hr}$ to $0600 \mathrm{hr}$ for all the activities discussed in the present investigation.

\section{Observations and Discussions}

\section{General Activity}

Individuals of both the species were active on the soil surface at different hours of night. During most of the day they took rest inside the tunnels. The innerside of the long and branched tunnels were coated with mucus. These tunnels opened-on the surface of the soil (fig. 1). Caecilians prefer existing tunnels rather than creating new ones everyday. This is evident as the number of holes on the surface remains unchanged for many days/weeks. It is worth investigating whether caecilians display similar behaviour in their natural habitat. If the openings of the tunnels are closed, new holes are seen the following morning This also confirms that caecilians are active at night. A declining trend in the activity was noticed between $0300 \mathrm{hr}$ and $0600 \mathrm{hr}$. These animals are not much disturbed with the dim light, but when subjected to bright light they remain motionless for a moment and soon start burrowing into the soil and disappear within a fraction of a minute. Sometimes at night they keep their head protruding out of the tunnels and retreat suddenly when disturbed. When kept in dark, the soil surface movement in terraria even during daytime is not uncommon. When caught by their head with half of their body inside the soil, they escape from the hold by pulling their body into the soil, thanks to the slimy skin. These observations are in conformity with that of $I$. glutinosus (Breckenridge et al., 1987). There is no distinct sexual dimorphism in caecilians. During breeding season females can be distinguished from males by the movement of yolky eggs in the abdominal cavity. Males can also be differentiated from the female by the phallodaeum, which gets protruded when the vent region of the male is pressed gently.

\section{Foraging Behaviour}

In captivity, when reared together, the individuals of both the species lived together without harming each other or showing cannibalistic behaviour. However, this requires further study as cannibalistic behaviour is reported by Seshachar and Iyer (1932) in I. glutinosus. No fighting was observed between individuals either for food or sex. Normally caecilians eat away earthworms one after the other at a time. However, many a times when entangled earthworms were offered to $I$. malabarensis with their heads protruded out of the tunnels, they snatched away the entire mass (fig. 2) and soon withdrew into the tunnels.

\section{Breeding Behaviour:}

Mate recognition, courtship and copulation: Courtship behaviour has been reported in only a few species of aquatic caecilians (Barrio, 1969; Murphy et al., 1977; Wilkinson, 1983), 
and on burrowing caecilians by Bhatta (1986). When males and females were placed together in a terrarium without soil, $I$. beddomei copulated several times irrespective of the breeding season. Further, when a male comes in contact with another individual moving in opposite direction, it invariably slides its ventral surface beneath the ventral surface of the other in an antero-posterior direction. If the other individual happens to be a female, she cooperates and assists the advancing male to press his cloaca and insert the phallodaeum into her vent. If unsuccessful in the first attempt, they repeat the process two or three times until successful copulation. The copulation (fig. 3) lasted for about 40 to 45 minutes. On the other hand, if the other individual happens to be a male he rejects the offer. As rightly pointed out by Wilkinson (1983) there was no twisting/ coiling of each other or climbing one above the other during copulation. They were in contact only by their rear ends and showed minimal movement during the copulation the female pulled rigorously to get away from the male.

Egg laying and parental care: The egg clutches of both the species were collected from the banks of natural streams during different periods of the year. I. beddomei eggs were collected between January-April and I. malabarensis eggs during AugustSeptember. The number of eggs in the egg clutches varied not only between different species but also between the individuals belonging to same species (Table 1). The egg clutches of $I$. beddomei contained $19+/-8$ eggs and weighed $4.4+/-2.0 \mathrm{~g}$., whereas those of $I$. malabarensis contained $86+/-8$ eggs and weighed $24.1+/-3.5 \mathrm{~g}$. respectively. I. malabarensis which was larger in body size, also had larger eggs and the volume of egg clutch (fig. 4) was greater than that of $I$. beddomei. Thus, a positive relationship between clutch size, clutch volume and body size is apparent in the two species. However, this relationship cannot be generalised for all the caecilians due to lack of observations. Interestingly, in a given egg clutch all the eggs resembled greatly in size and development stages in both the species. Though the two species showed different pattern of coiling (fig. $5 \& 6$ ), the acts involved in the parental care were almost the same. The mother used to remain coiled around the egg clutch for most of the time and kept them moist. She changed the position of egg clutches by moving them to different places and also rotating them frequently. When five mothers and five egg clutches of $I$. beddomei were put together they guarded different egg clutches at different times. Once, even a single mother guarded three egg clutches (fig. 5) belonging to three different mothers. Perhaps the mother is incapable of distinguishing her own clutch. At later stages of development, mothers abandoned their egg clutches. Balakrishna et al. (1982) reported the collection of two egg clutches with eggs in advanced stage of development without the mother guarding them. Thus, parental care does not seem to last all through the period of embryonic development, which needs thorough investigation. Further, Seshachar et al., (1982) have reported the collection of an egg clutch of $I$. malabarensis without any
Table 1. Egg clutch size and weight

\begin{tabular}{|c|c|c|c|c|}
\hline & \multicolumn{2}{|c|}{ I. beddomei } & \multicolumn{2}{|c|}{ I. malabarensis } \\
\hline & $\begin{array}{l}\text { \# of } \\
\text { eggs }\end{array}$ & $\begin{array}{l}\text { Weight } \\
\text { (in g.) }\end{array}$ & $\begin{array}{l}\text { \# of } \\
\text { eggs }\end{array}$ & $\begin{array}{l}\text { Weight } \\
\text { (in g.) }\end{array}$ \\
\hline 1 & 24 & 5.2 & 78 & 23.5 \\
\hline 2 & 29 & 5.8 & 82 & 24.3 \\
\hline 3. & 28 & 7.5 & 88 & 18.2 \\
\hline 4 & 6 & 1.7 & 101 & 29 \\
\hline 5 & 13 & 2.9 & 81 & 25.6 \\
\hline 6 & 16 & 3.1 & & \\
\hline Avg & 19 & 4.4 & 86 & 24.1 \\
\hline s.d. & 8 & 2.0 & 8 & 3.5 \\
\hline
\end{tabular}

detectable embryos in the eggs. They suspected that unfertilized eggs were laid by $I$ malabarensis. Their observation also requires further study, as one of the egg clutches (with 88 eggs) collected during this investigation also did not show any embroys on the day of collection, but within three days embryos became apparent simultaneously in all the eggs.

Some of the behaviour during maternal care are worth mentioning. While attempting to take away an egg clutch from her custody, the mother bit gently the interrupting finger of the observer. In another instance, she held onto the egg clutch by biting the jelly string joining the eggs. Sanderson (cited in Salthe Mecham, 1974) reported similar behaviour in Idiocramium russelli, where the female defended the egg clutch by spitting water at him. Since the eggs were in the same stage of development and hatched simultaneously within a day or two indicated that the eggs were laid within a short span of time irrespective of the number of eggs. This is true for both the species. During this study it was noticed that I. beddomei laid a clutch of 23 eggs within 36 hours. The hatched larvae were out in water for two days, lost their external.gills and invaded into the soil as observed in I. glutinosus (Breckenridge et al., 1987).

The study of only two species belonging to the same genus is inadequate to generalise this behaviour to the whole group of caecilians. Certainly, there is a necessity to observe these behaviour in the individuals of other three genera viz., Gegeneophis, Uraeotyphlus and Indotyphlus.

\section{Acknowledgement}

The author is grateful to Prof. Madhav Gadgil, Centre for Ecological Sciences, Indian Institute of Science, Bangalore for his encouragement and financial support through PEW Foundation Grant. 

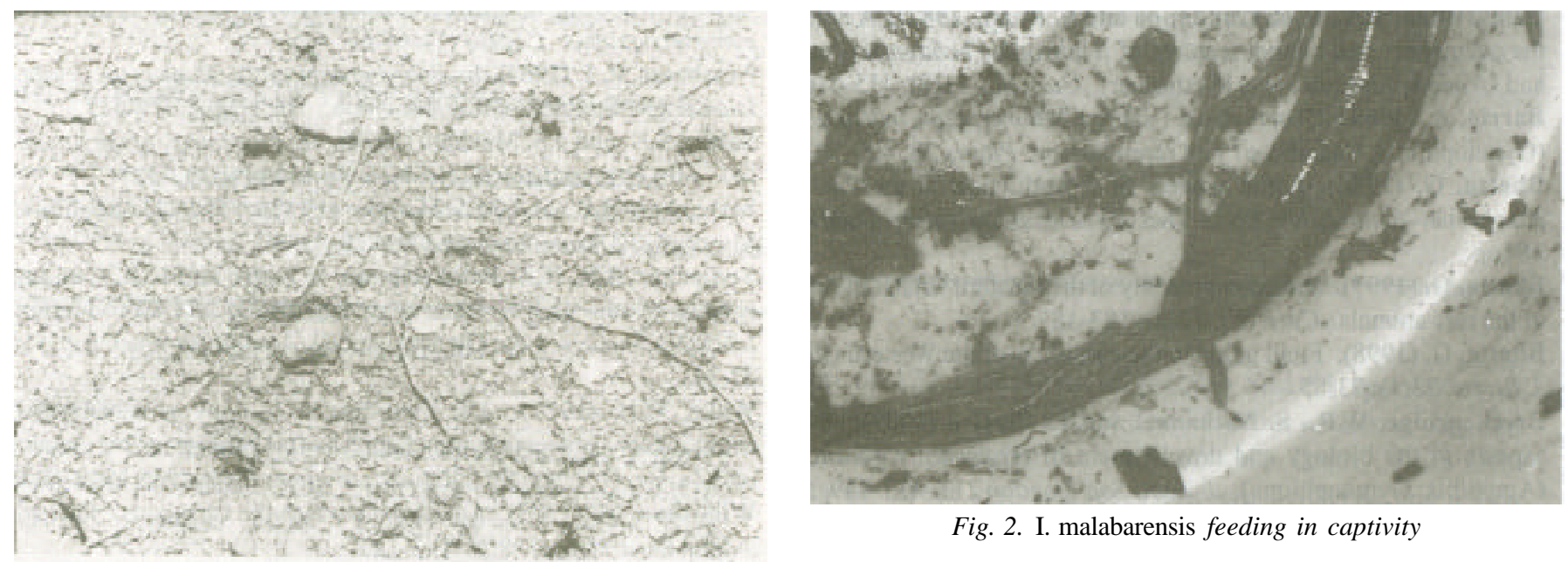

Fig. 1. Tunnel openings by I. malabarensis
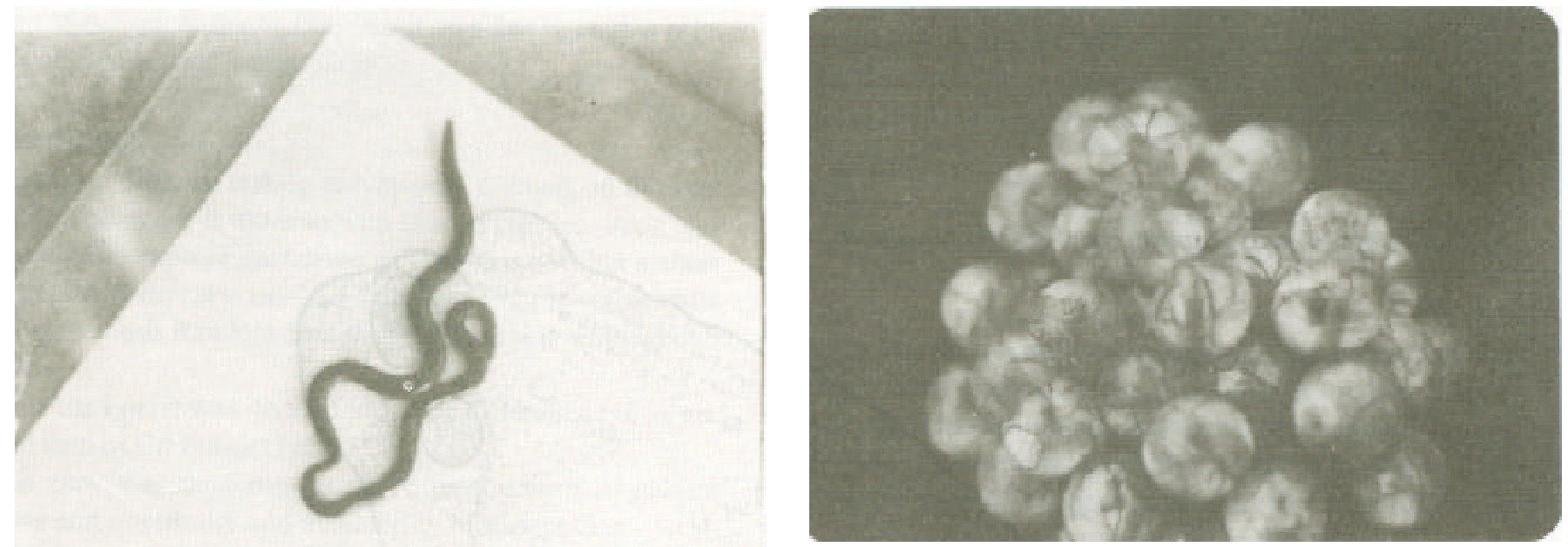

Fig. 4. Egg clutch of I. beddomei

Fig. 3. Copulation in I. beddomei

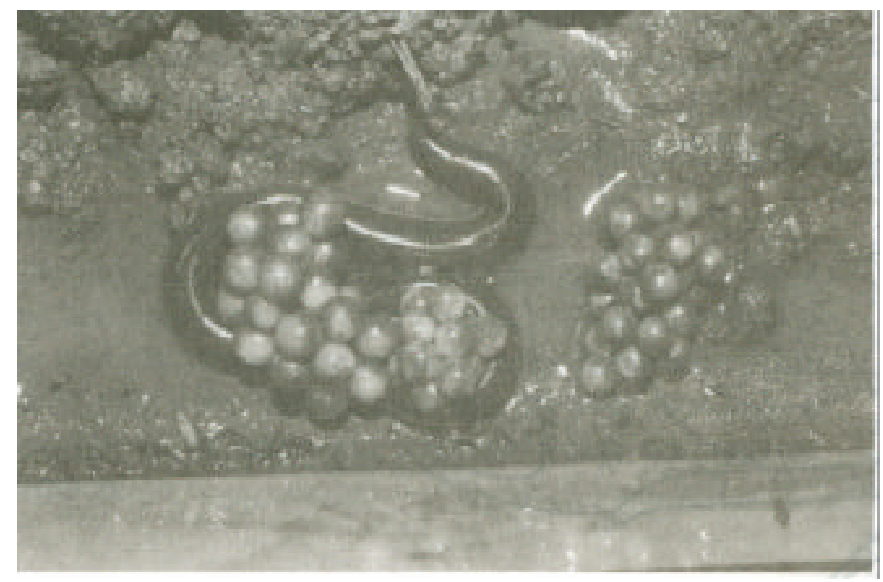

Fig. 5. Parentel care by I. beddomei

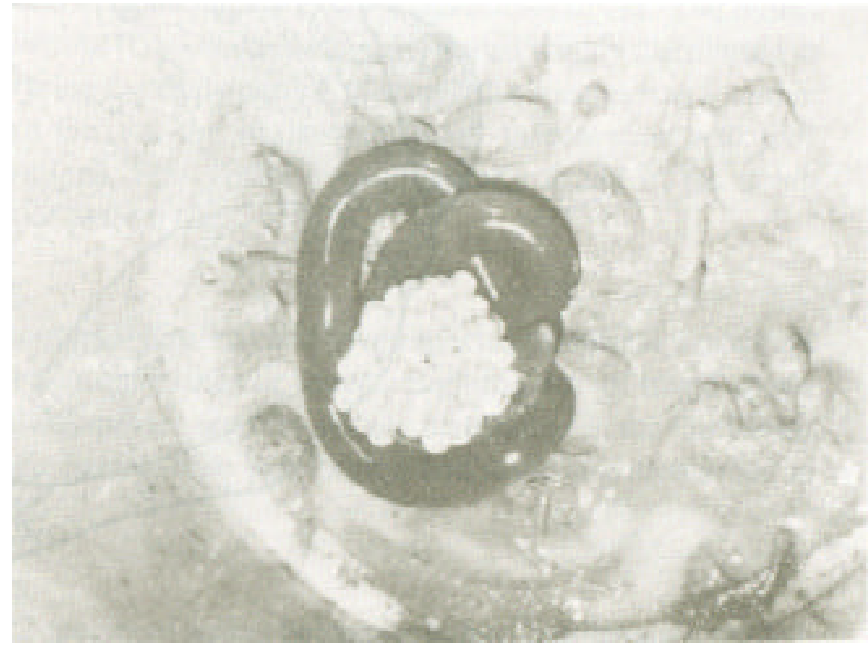

Fig. 6. Parentel care by I. malabarensis 


\section{References}

Balakrishna; T.A., K.R. Gundappa and S. Katre (1982). A note on the occurrence and habitat features of Ichthyophis beddomei (Peters) and Uraeotyphlus narayani (Seshachar). Curr. Sci. 51(8): 415-416.

Barrio, A. (1969). Observationes sobre Chthonerpeton indistinctum (Gymnophiona, Caecilidae) y su reproduction. Physis 28: 499-503.

Bhatta, G. (1986). Some aspects of reproduction in the Apodan Amphibian -Ichthyophis. Ph.D. Thesis. Karnatak University, Dharwad, $281 \mathrm{pp}$.

Bhatta, G. (1997). Caecilian diversity of the Western Ghats: In search of the rare animals. Curr. Sci. 73(2): 183-187.

Bhatta, G. (1998). Field guide to the caecilians of the Western Ghats. J. Biosci. 23(1): 73-85.

Breckenridge, W.R., S. Nathanael and L. Pereira (1987). Some aspects of the biology and development of Ichthyophis glutinosus (Amphibia: Gymnophiona). J. Zool. Soc. London 211: 437-449.

Murphy, J.B., H. Quinn and J.A. Campbell (1977). Observations on the breeding habits of the aquatic caecilian Typhlonectes compressicaudus. Copeia (1): 66-69.

Nussbaum, R.A. (1984). In: Biogeography and ecology of the Seychelles Islands (ed. Stoddart, D.R.), Junk Pub., The Hague 379-415.

Salthe, S.N. and J.S. Mecham (1974). In: Physiology of the Amphibia (ed Lofts, B.) Academic Press, New York, Vol.II 309-521.

Seshachar, B.R. and M.S.M. Iyer (1932). The Gymnophiona of Mysore. J. Mysore Univ. 6: 171-175.

Seshachar, B.R., T.A. Balakrishnan, S. Katre and K.R. Gundappa (1982). Some unique features of egg laying and reproduction in Ichtyophis malabarensis (Taylor) (Apoda, Amphibia). Curr. Sci., 51(1): 32-34.

Wake, M.H. (1977). The reproductive biology of caecilians: An evolutionary perspective, In: Reproductive biology of the amphibia (eds Taylor, D.H. and S.I. Guttman), Plenum Press, New York 73-102. Wilkinson, M. (1983). An introduction to the caecilians - the legless amphibians. Herptile 8(4): 143-147.

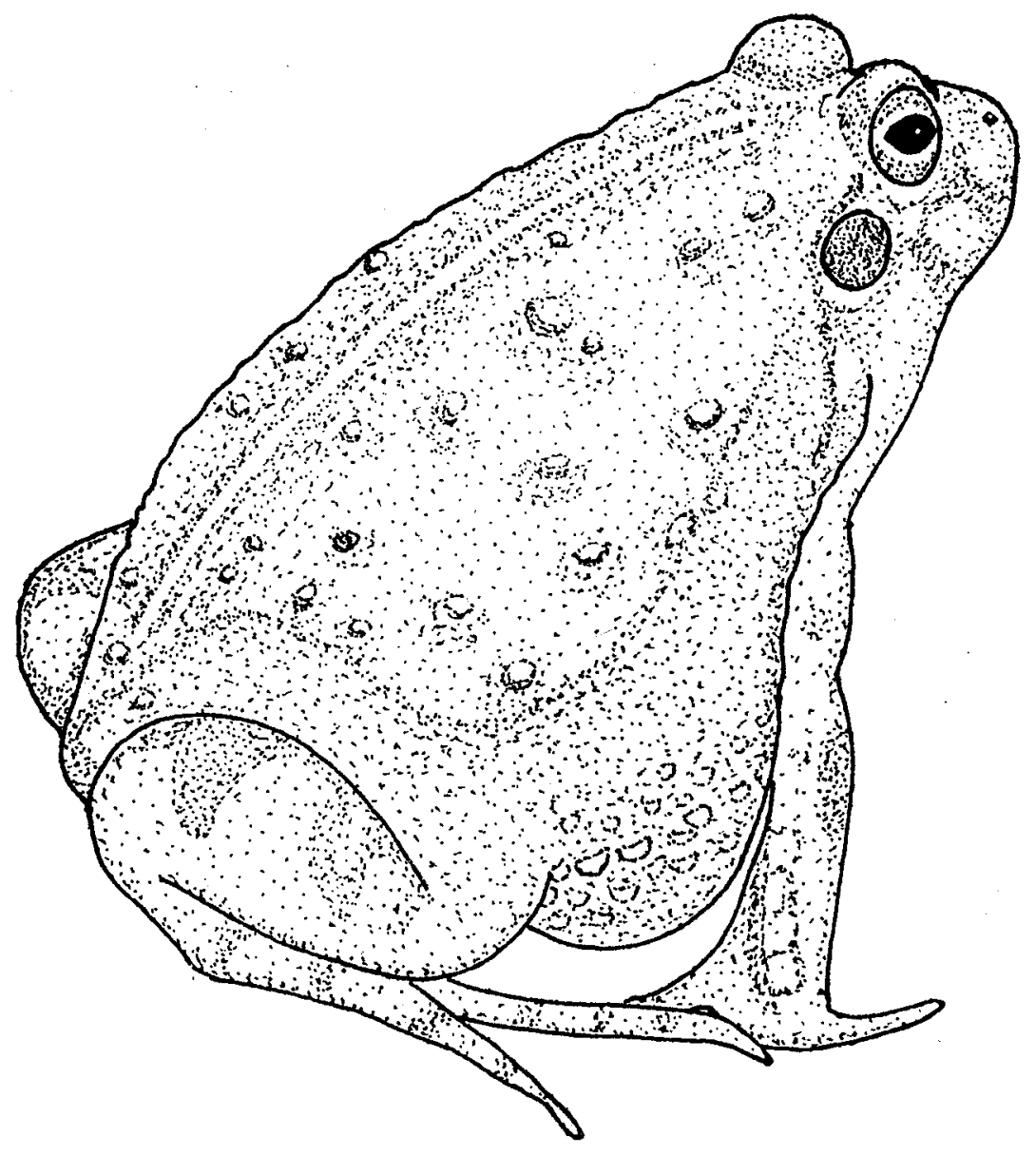

